\title{
Antioxidant activity in selected fresh vegetables in Jaffna
}

\author{
M G A N Karunasiri, N Ravimannan*, P Sevvel \\ Department of Botany, Faculty of Science, University of Jaffna, Jaffna, Sri Lanka. \\ *Email:nravi@jfn.ac.lk
}

\begin{abstract}
Generally, fruits and vegetables are very good source of natural antioxidants which consists of many different antioxidant components. Though there are many vegetables available in the markets with high antioxidant values and high mineral composition, most of them are very expensive. Hence as an alternative source of minerals and antioxidants the possibility of consuming conventional vegetables was taken into consideration in this study. The procedure was carried out to determine the antioxidant activity based on the inhibition of the free radical 2,2'-diphenyl-1-picrilhydrazil (DPPH) in ethanol extract of the okra (Abelmoschus esculentus L.), beetroot (Beta vulgaris L.), bitter gourd (Momordica charantia L.), brinjal (Solanum melongena L.), tomato (Solanum lycopersicum L.), banana peppers (Capsicum annuит), green chili (Capsicum annuит L.), carrot (Daucus carota), yard long beans (Vigna unguiculata subsp. sesquipedalis) and beans (Phaseolus vulgaris L.). According to the results, okra had the highest $\mathrm{EC}_{50}$ value $(9.255 \pm 0.130 \mathrm{mg} / \mathrm{mL})$ while beetroot had the lowest $\mathrm{EC}_{50}$ value $(0.743 \pm 0.032 \mathrm{mg} / \mathrm{mL})$ among the tested vegetables. It showed that Okra had the lowest antioxidant activity while beetroot had the highest antioxidant activity. Beetroot got the lowest $\mathrm{EC}_{50}$ value which was higher than the standard L-Ascorbic acid $(0.005 \pm 0.001 \mathrm{mg} / \mathrm{mL})$. $\mathrm{EC}_{50}$ of all the tested vegetable samples are significantly different from each other as well as from L-Ascorbic acid. Considering these results, the local vegetables mentioned above also contain high antioxidant activities and can be included in our diet to lead a healthy life.
\end{abstract}

Keywords - Antioxidants, DPPH method, $\mathrm{EC}_{50}$ value, Radicals, Vegetables

\section{INTRODUCTION}

Usually all fruits and vegetables have many phytochemicals which possess various bioactivities. It includes antioxidants. Consumers can open themselves to more antioxidants through their diet consisting of fruits and vegetables which is extremely easy and best way (Brookie et al., 2018). By consuming fruits and vegetables, we can reduce the risk of oxidative damages to cells (Sun et al., 2002). Fruits and vegetables are very good sources of natural antioxidants (Justina et al., 2013). Hence those are alluded to as "super foods" or "functional foods" (Megan, 2015). These antioxidants are carotenoids, vitamins, phenolic compounds, flavonoids, dietary glutathione and endogenous metabolites (Justina et al., 2013). Phenolics found in fruits and vegetables possess a broad spectrum of biochemical activities such as antioxidant, anticarcinogenic and antimutagenic properties (Nakamura et al., 2003 and Tapiero et al., 2002). Thus according to the previous researches it has been highly recommended to include proper combination of fruits and vegetables in daily diet, whose phytochemicals synergistically act to reduce the risk of degenerative diseases like cardiovascular disease and cancer (Deepa et al., 2015).

Previous studies have shown that the importance of vegetables in a healthy diet and to prevent degenerative diseases that is caused by oxidative stress (Sreeramulu et al., 2010). The antioxidant compounds like vitamins and phytochemicals, such as ascorbic acid, carotenoids, polyphenols and fibre have been regarded as the bioactive substances responsible to fight against these effects (Szeto et al., 2004). Based on various studies on the antioxidant compounds in several vegetables the aim of current research was focused on determination of antioxidant activity of local vegetables which are less expensive.

\section{Materials AND MethodS}

\section{A. Vegetables used in this study}

Tomato (Solanum lycopersicum L. [Solanaceae]), Beetroot (Beta vulgaris L. [Amaranthaceae]), Carrot (Daucus carota L. [Apiaceae]), Bitter gourd (Momordica charantia L. [Cucurbitaceae]), Brinjal (Solanum melongena L. [Solanaceae]), Bean (Phaseolus vulgaris L. [Fabaceae]), Banana pepper (Capsicum annuum [Solanaceae]), Yard long bean (Vigna unguiculata subsp. Sesquipedalis L. [Fabaceae]), Okra (Abelmoschus esculentus L. [Malvaceae]) and green chilli (Capsicum aпnиит L. [Solanaceae]) were purchased from local farmers in Jaffna. The identification was done by a taxonomist in the University of Jaffna. Fruits of tomato, bitter gourd, brinjal and chili were used in this study. Roots of beet and carrot were used. Seeds were used from banana pepper and pods were used from yard long bean and Okra.

\section{B. Determination of antioxidant activity and $E C_{50}$ values}

The procedure was carried out to determine the antioxidant activity (AC) in the formulation which was proposed by Williams et al. (1995). It is based on the inhibition of the free radical 2, 2'-diphenyl-1-picrilhydrazil (DPPH) in ethanol extract of the samples. Here a modified version was applied following recommendations by Molyneux (2004).

To evaluate the antioxidant activity in fresh vegetable samples, each sample was taken directly after washing. Each sample ( $2 \mathrm{~g}$ ) was taken and ground by using motor and pestle. Then after adding $10 \mathrm{~mL}$ of ethanol (96\%) it was allowed to stir for 40 minutes at room temperature and then centrifuged for 10 minutes at $10,000 \mathrm{~g}$ to retain the supernatant.

The volume of the extract ranged from 0 to $100 \mu 1$ and mixed in test tubes, with $2 \mathrm{~mL}$ of an ethanol solution of DPPH 40 ppm, prepared on the same day under dark conditions. Then 
ethanol was added to that until the final volume became $3 \mathrm{~mL}$. After 30 minute incubation in dark at room temperature the absorbance was taken at $517 \mathrm{~nm}$ by using a spectrophotometer. The experiment was carried out in three replicates.

The percentage of inhibition is calculated by using the following equation for each extract.

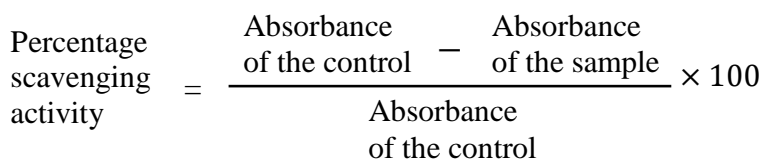

After plotting the graph (concentration of DPPH solution vs percentage scavenging activity), the $\mathrm{EC}_{50}$ values of each sample were determined and antioxidant activity is expressed as $\mathrm{mg} / \mathrm{mL}$. Ascorbic acid was taken to draw a standard curve to compare the results instead of vegetable samples.

\section{DATA ANALYSIS}

Values were expressed as mean \pm SD of three replicates. Means were analyzed by Duncan's test using SPSS software (IBM SPSS statistical software).

\section{RESULTS AND DISCUSSION}

According to the results okra got the highest $\mathrm{EC}_{50}$ value $(9.26 \pm 0.13 \mathrm{mg} / \mathrm{mL})$ while beetroot got the lowest $\mathrm{EC}_{50}$ value $(0.74 \pm 0.03 \mathrm{mg} / \mathrm{mL})$ among these vegetables. It showed that okra had the lowest antioxidant activity while beetroot had the highest antioxidant activity among these selected vegetables. Okra had required high concentration of the extract to require $50 \%$ scavenging of radicals under experimental conditions that had been used while beetroot required low concentration of the extract to $50 \%$ scavenging of radicals under experimental conditions that had been used.

Though beetroot got lowest $\mathrm{EC}_{50}$ value among these selected vegetables, that $\mathrm{EC}_{50}$ value is lower than the standard sample that was L-Ascorbic acid $(0.005 \pm 0.001 \mathrm{mg} / \mathrm{mL})$. None of the samples showed significantly more or less similar $\mathrm{EC}_{50}$ for standard L-Ascorbic acid. All the selected vegetable samples are significantly different from each other as well as from L-Ascorbic acid.

The $\mathrm{EC}_{50}$ values reduced significantly $(\mathrm{p}<0.05)$ in the following order; A. esculentus L. $(9.255 \pm 0.130 \mathrm{mg} / \mathrm{mL})>$ M. charantia L. $(6.532 \pm 0.83 \mathrm{mg} / \mathrm{mL})>S$. melongena $\mathrm{L}$. $(5.785$ $\pm 0.022 \mathrm{mg} / \mathrm{mL})>$ L. lycopersicum $\mathrm{L} .(3.243 \pm 0.137 \mathrm{mg} / \mathrm{mL})>$ C. annuит (banana pepper) $(3.151 \pm 0.079 \mathrm{mg} / \mathrm{mL})>$ C. annuиm $\mathrm{L}$. (chilli) $(2.702 \pm 0.074 \mathrm{mg} / \mathrm{mL})>$ D. carota $(1.893 \pm 0.018 \mathrm{mg} / \mathrm{mL})$ $>$ V. unguiculata L. $(1.476 \pm 0.095 \mathrm{mg} / \mathrm{mL})>P$. vulgaris L. $(1.066 \pm$ $0.074 \mathrm{mg} / \mathrm{mL})>$ B. vulgaris L. $(0.743 \pm 0.032 \mathrm{mg} / \mathrm{mL})$. The results are presented in Table 1 and Figure 1 given below. Conversely DPPH antioxidant activity increased significantly among the vegetables.

The results obtained showed that local vegetable have high antioxidant activities and there is variation in the content. The results regarding antioxidant activities are in par with the previous studies done by Scarano et al. (2018) in carrot and
Karagyozov et al. (2013) and Guldiken et al. (2016) in beetroot. Also the antioxidant activity in Okra found in the present research is supported by the previous studies done by Lianmei et al. (2014). In this study, a modified DPPH method (Molyneux, 2004) is used to determine the antioxidant activity which is a very common method. Various other methods can also be tried in future studies including processed vegetables as well. The present study reveals that fresh vegetables provide sufficient amounts of antioxidants if they are included in the regular diet.

\begin{tabular}{lc}
\multicolumn{2}{c}{ Table 1: Antioxidant activity of fresh vegetables } \\
\hline Sample & EC $_{\mathbf{5 0}}$ value $(\mathbf{m g} / \mathbf{m L})$ \\
\hline Banana pepper & $3.15 \pm 0.08^{\mathrm{a}}$ \\
Beans & $0.74 \pm 0.03^{\mathrm{c}}$ \\
Beet & $6.53 \pm 0.08^{\mathrm{d}}$ \\
Bitter gourd & $5.78 \pm 0.02^{\mathrm{e}}$ \\
Brinjal & $1.89 \pm 0.02^{\mathrm{f}}$ \\
Carrot & $2.70 \pm 0.07^{\mathrm{g}}$ \\
Chili & $9.26 \pm 0.13^{\mathrm{h}}$ \\
Ladies fingers & $1.48 \pm 0.10^{\mathrm{i}}$ \\
Yard Long beans & $3.24 \pm 0.14^{\mathrm{a}}$ \\
Tomato & $0.005 \pm 0.00026^{\mathrm{j}}$
\end{tabular}

Values with different alphabets are significantly different $(\mathrm{p}<0.05)$

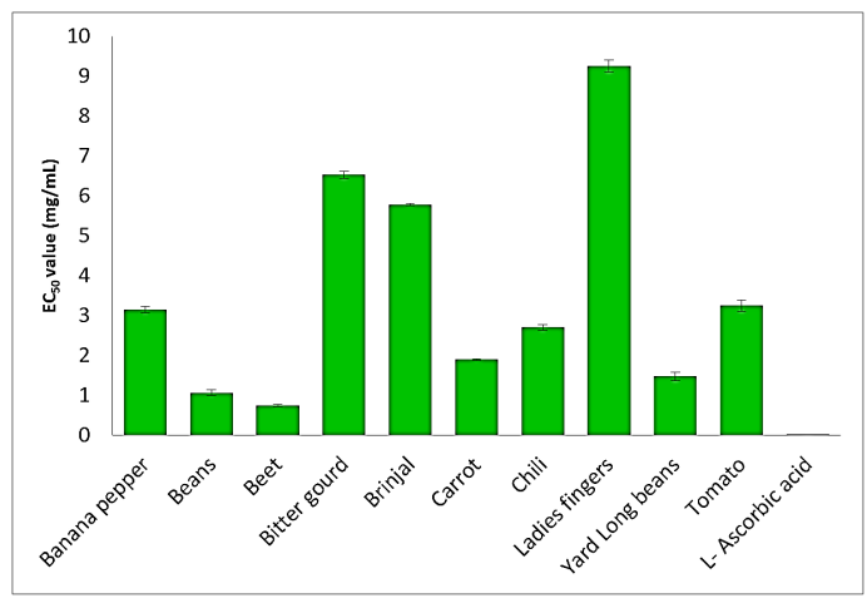

Figure 1. $\mathrm{EC}_{50}$ values of fresh vegetables.

\section{Conclusion}

The local vegetables also contain high antioxidant activities. Considering these results, nutritional levels in our diet can be increased by the vegetables that could be grown in our home gardens. Due to the growing demand for organic vegetables at present the current research in developed countries are mainly concerned about increasing the antioxidant content in vegetables by using various combinations of natural fertilizers. 
In this research further studies should be done to find the changes in the antioxidant activities in vegetables after processing and consumers should be advised to follow proper cooking methods to avoid the loss of antioxidants during cooking.

\section{REFERENCES}

Brand-Williams, W., Cuvelier, M. and Berset, C. (1995). Use of a free radical method to evaluate antioxidant activity. Lebensm Wissenschaft Technol 28, 25-30.

Brookie, K. L., Best, G. I and Conner, T. S. (2018). Intake of raw fruits and vegetables is associated with better mental health than intake of processed fruits and vegetables. Frontiers in Psychology 9, 487-487.

Deepa, P., Lavanya, B., Sasirekha, G. V. and Santhi, M. (2015). Phytochemical Screening, Antioxidant and Antidiabetic Activity of Musa acuminata, Citrus sinensis and Phyllanthus emblica. American Journal of PharmTech Research 5 (2), 2249-3387.

Guldiken, B., Toydemir, G., Nur Memis, K., Okur, S., Boyacioglu, D. and Capanoglu, E. (2016). Home- processed red beetroot (Beta vulgaris L.) Products: Changes in antioxidant properties and bioaccessibility. International Journal of Molecular Sciences 17, 858-858.

Zykevičiūtè-Laugks, L., Česonienè, L. and Karklelienè, R. (2013). The influence of the sample preparation of carrots (Daucus carota L. Neptun) on the antioxidant activity and phenolic compounds. Biologija 59(2), 187-194.

Karagyozov, V., Denev, P., Kratchanova, M. and Kratchanov, C. (2013). Antioxidant activity of red beet juices obtained after microwave and thermal pretreatments. Czech Journal of Food Sciences 31(2), 139-147.
Hu, L., Yu, W., Li, Y., Prasad, N. and Tang, Z. (2014). Antioxidant activity of extract and its major constituents from Okra seed on rat hepatocytes injured by carbon tetrachloride. BioMed Research International.

Megan, W. (2015). Antioxidants: Health Benefits and Nutritional Information, http://www.medicalnewstoday.com/articles/301506.php

Molyneux, P. (2004). The use of the stable free radical diphenylpicrylhydrazyl (DPPH) for estimating antioxidant activity. Journal of Science and Technology 26(2), 211-219.

Nakamura, Y., Watanabe, S., Miyake, N., Kohno, H. and Osawa, T. (2003). Dihydrochalcones: evaluation as novel radical scavenging antioxidants. Journal of Agricultural and Food Chemistry 51, 3309-3312.

Scarano, A., Gerardi, G., D’Amico, L., Accogli, R. and Santino, A. (2018). Phytochemical analysis and antioxidant properties. Agriculture 8,102-102.

Sreeramulu, M. D. and Raghunath, M. (2010). Antioxidant activity and phenolic content of roots, tubers and vegetables commonly consumed in India. Food Res. Int. 43: 1017-1020.

Sun, J.1., Chu, Y. F., Wu X. and Liu, R. H. (2002). Antioxidant and antiproliferative activities of common fruits. J Agric Food Chem. 50(25): 7449-54.

Szeto, Y. T., Kwok, T.C. and Benzie, I. F. (2004). Effects of a long-term vegetarian diet on biomarkers of antioxidant status and cardiovascular disease. Nutrition. 4(20): 863-866.

Tapiero, H., Tew, K. D., Ba, G. N. and Mathe, G. (2002). Polyphenols: do they play a role in the prevention of human pathologies? Biomed. Pharmacother. 56: 200-207. 
